\title{
South African nurse managers' perceptions regarding cost containment in public hospitals
}

\author{
ET Ntlabezo, D Litt et Phil student, Department of Health Studies, UNISA \\ VJ Ehlers, Department of Health Studies, UNISA \\ SW Booyens, Department of Health Studies, UNISA
}

\section{Summary}

The perceptions of nurse managers regarding cost containment issues in selected public hospitals in the Port Elizabeth metropole of the Eastern Cape were investigated. Results indicated that nurse managers required better preparation for their cost control responsibilities. Although the majority of the nurse managers realised that staffing issues affected cost containment efforts, they were reportedly unable to prevent nurses from leaving their points of duty without due authorisation, curb the rate of absenteeism or reduce the number of resignations. Nurse managers suggested that cost containment efforts would benefit from effective security checks to curb losses of stock and equipment, including wheelchairs, and that more public telephones should be installed in hospitals. Rationalisation of staff and specialised services among the four major hospitals could further enhance cost containment efforts.

Key concepts: budgeting, cost containment, fiscal accountability, health care costs, hospital management, nurse manager

\section{Opsomming}

Die houdings en persepsies van verpleegbestuurders aangaande vraagstukke om kostes in bedwang te hou, is ondersoek in die Port Elizabeth metropool in die Oos Kaap. Die resultate het aangetoon dat die verpleegbestuurders beter voorbereiding benodig ten opsigte van hulle verantwoordelikhede betreffende die beheer van kostes. Alhoewel die meeste verpleegbestuurders besef het dat personeelvraagstukke kostebeheermaatreëls beïnvloed, was hulle desnieteenstaande nie daartoe in staat om te verhoed dat verpleegkundiges hulle dienspunte sonder behoorlike goedkeuring verlaat nie, om die afwesigheidssyfer te laat krimp nie, of om die aantal bedankings te laat afneem nie. Verpleegbestuurders het voorgestel dat kostebeheermaatreëls sou baat vind by doeltreffende sekuriteitskontroles van voorraad en toerusting, insluitende rolstoele en dat meer openbare telefone in hospitale geïnstalleer moet word. Die rasionalisering van personeel en gespesialiseerde dienste tussen die vier hoofhospitale kan kostebeheermaatreëls tot verdere voordeel strek.

\section{Introduction}

The nurse manager must have the necessary information and preparation to develop strategic financial planning, because the nursing division often accounts for more than half of health care institutions' budgets (Zachray, Gilbert \& Gragg 1995:49). The ever-shrinking health service budgets mean that nurse managers need to possess substantial financial skills (Caroselli 1996:292). A study on the economic awareness of nurses in relationship to budgetary control, demonstrated that nurses who worked with a nurse manager who maintained budgetary control had a greater economic awareness and consumed fewer supplies and equipment than nurses who worked with a nurse manager without such skills (Caroselli 1996:292). Changing financial environments and economic uncertainties in the health care industry continue to reduce the resources available for health care services (Bultema 1995:38). Nurse managers, as leaders in the nursing profession, need to contribute effectively to financial management and to cost containment efforts of health care institutions.

\section{Background to the problem}

Nurse managers face the dilemma of maintaining high-quality patient care standards, while simultaneously cutting costs of services rendered. Research on the position of the nurse manager identified "solving fiscal problems" to be a common concern in different health care settings (Sengin \& Dreisbach 1995:34). Hospitals tend to admit only patients with high acuity level conditions in an effort to decrease health care costs (Warren \& Rozelle 1995:51). At all 
levels of health care, nurses are the main users of resources by virtue of their direct links with the patients and because nurses constitute the largest group of health care professionals. Therefore, they need to be cautious about their use of resources and about their selection of items and equipment, in order to contain costs. As nurse managers' perceptions regarding cost containment issues could influence the success or failure of cost containment efforts in public hospitals, it was deemed desirable to identify and describe these perceptions in an attempt to enhance cost containment efforts in public hospitals in South Africa.

The nurse manager's responsibility in the control of financial resources is extended beyond looking solely at the nursing department. The following aspects of financial management are required by a nurse manager for effective participation in cost containment efforts: budget forecasting in health care; cost-benefit analysis in health care; unit budgetary control measures in hospitals; procurement of financial resources for the hospital; monitoring of financial resources in individual units (Chase 1994:56). The nurse manager, as a team leader, needs to be acutely aware of the state of the hospital's resources in order to produce the best quality treatment with the available resources within the budgetary constraints.

The nurse manager is involved in making decisions regarding financial expenditure and budgets of the hospital. Large sums of money are spent on hospital maintenance and on running costs. The nurse managers' perceptions of cost containment issues could influence the decisions taken and actions implemented impacting on the successes or failures of cost containment efforts. Situations that indirectly affect the hospital's financial status negatively, and where the nurse managers' perceptions could exert some intluence, include

- absenteeism of staff and general misuse of state health time by employees

- $\quad$ shrinkage of stock, caused by unauthorised removal of hospital property

- $\quad$ improper or careless use of hospital equipment, resulting in breakages and/or increased maintenance costs

- theft and misuse of and damage to costly items like wheelchairs

- misuse of telephone services.

\section{Purpose of the study}

The purpose of the study was to identify perceptions of nurse managers regarding cost containment issues. Based on this knowledge course outlines could be produced to enlighten nurse managers about relevant cost containment issues in public hospitals.

\section{Objectives of the study}

The survey attempted to identify whether nurse managers perceived

- their preparation/orientation towards cost contain- ment to be adequate

- $\quad$ staff issues, leaving points of duty, absenteeism and resignations of nurses to impact negatively on hospitals' cost containment issues

- the acquisition and control of supplies and equipment to influence cost containment efforts

- concerning the misuse of wheelchairs and telephones and the possible impact(s) on cost containment efforts

- general cost containment efforts to enhance the success of hospitals' cost containment efforts.

\section{Research questions}

Nurse managers are responsible for managing the nursing personnel budgets as well as large portions of the hospitals' budgets for equipment and supplies. Hospital cost containment efforts would only be successful if nurse managers could implement such efforts effectively. However, such effective implementation of cost containment efforts would be influenced by nurse managers' perceptions about hospitals' cost containment efforts/issues. This study attempted to identify nurse managers' perceptions of cost containment issues in public hospitals in the Port Elizabeth Metropole. Such knowledge about nurse managers' perceptions could be used to design in-service and continuing education programmes to enhance nurse managers' cost containment skills in future. This study was designed to attempt to answer the following research questions, related to the previously stated objectives of the study:

- How do nurse managers perceive their preparation/ orientation towards cost containment?

- What are the perceptions of nurse managers regarding staff matters which influence cost containment, for example, leaving points of duty, absenteeism and resignations?

- What are nurse managers' perceptions regarding measures to contain and control the use, as well as the acquisition, of supplies and equipment?

- What are nurse managers' perceptions regarding measures to contain and control problems created by the misuse of wheelchairs and telephones?

- Which general cost containment measures are perceived by nurse managers as being important in addition to those already stated?

\section{Assumptions underlying the study}

Assumptions are basic principles that are assumed to be true on the basis of logic and reason without proof or verification (Polit \& Hungler 1993:431). The following assumptions served as points of departure for the research:

- Nurse managers are cost conscious health care professionals.

- Lack of knowledge of financial and costs containment issues hamper nurse managers' inputs rendered 
at top level management meetings concerning cost containment decisions.

- Nurse managers are not aware of the implications of employee absenteeism on a hospital's cost containment efforts

- Nurse managers are aware of the relationship between productivity and costs.

\section{Scope of the study}

The study was limited to four general hospitals, functioning under the Department of Health of the Port Elizabeth Metropole of the Eastern Cape (South Africa's fourth largest metropole). The hospitals offer clinical health services to the communities they serve. They also offer basic and postbasic clinical assistance to the various types of students in the health professions, allocated periodically to the hospital wards and departments for practical experience. The four hospitals were selected because they had bed capacities exceeding 200 and offered specialised medical treatment facilities. These large hospitals with bed capacities of $247,390,654$ and 789 respectively, incur a large proportion of the Eastern Cape's total health care expenditure.

\section{Operational definitions}

Under this heading the key concepts are defined and explained to clarify terminology used throughout this article.

\section{Perception}

According to the Oxford Handy Dictionary (1991:656), to exercise perception means to apprehend with the mind, to understand, to observe, using one of the senses, especially sight.

\section{Nurse manager}

In this study a nurse manager will be seen as a nurse leader whose responsibilities include cost containment in hospitals. Reference in this study to the nurse manager includes nursing personnel members at the head of the nursing division (top-level managers), and nurse supervisors in wards and departments (first-level and middle-level managers). Horvath, Secatore, Alpert, Costa, Powers, Stengrevics and Aroian (1994:39) define the unit nurse manager (first level nurse manager) as the one who holds a 24-hour accountability for the units within a health care agency; who is closest to the point of care delivery, and who manages the activities that facilitate delivery of health care services.

\section{Selected hospitals}

The term "selected hospitals" in this study refers to the chosen provincial hospitals within the boundaries of the Eastern Cape Province. A hospital is defined in The Oxford Handy Dictionary (1991:417) as an institution providing medical and surgical treatment for persons ill or injured. The four hospitals were selected because they had bed capacities exceeding 200 and offered specialised medical treatment facilities.

\section{Cost containment}

The dictionary defines the term "cost" as "expenditure; price; worth; charge; or payment" (Collins Thesaurus 1993:201). In this study the term "cost" refers to the expenditure incurred in rendering patient care, as well as the general running and maintenance of a hospital. "Containment" is derived from the verb "to contain" which, according to The Oxford Handy Dictionary (1991:173) means "to hold; to enclose; to have capacity for". "Cost containment" will, therefore, be used as meaning control of expenditure in a hospital situation. Cost containment includes methods of control of expenditure and prevention of financial wastage.

\section{Methodolody}

A descriptive survey was conducted to identify the perceptions of the nurse managers concerning cost containment in the selected public hospitals.

\section{Population}

The population for this study consisted of all nurse managers occupying managerial posts in the four participating public hospitals during the period of study. For the purpose of this study, nurse managers included the following categories:

- all registered nurse managers or their deputies in charge of nursing units, regarded as first-level managers.

- all chief professional nurses engaged in nurse supervisory activities in hospital departments, or areas constituting wards and units, functioning as middle-level managers.

- chief professional nurses involved in decision-making and hospital policy formulations for cost containment measures, functioning as top-level managers.

The total number of managers at top level were 12 and for those in the middle and first level combined totalled 288. As this population of nurse managers was relatively small, no sampling procedures were employed. The entire population of nurse managers was studied.

\section{Research instrument}

The research instrument was a questionnaire, comprising closed ended statements and open ended questions. The participants were requested to indicate the degree of importance they attached to each statement according to a four-point Likert scale, varying from 'unimportant' to 'extremely important'. Questionnaires could be used because all the respondents were educated professional nurses who could read and interpret the questionnaire items in English, obviating the need to translate the questionnaire. The open ended questions required the respondents to portray their perceptions concerning each issue addressed in a specific question. Different sections of the questionnaire attempted to obtain information about respondents' biographic data, their preparation in budgetary and financial matters, orientation received about budgetary and financial management, 
cost containment as influenced by productivity, personnel problems, control of supplies, equipment and stock losses.

On pretesting the questionnaire, expert opinions were elicited from eleven senior nurse managers, who did not participate in the actual research. These experts agreed that the questionnaire items were relevant to the research topic and that the questions were clearly formulated. No items required changing. However, these nurse managers requested that no specific hospital should be recognisable in the report in order to ensure the anonymity not only of individual participants but also of the participating hospitals. Thus the results had to portray only the combined results for the four hospitals so that no individual hospital could be identified, making it impossible to compare and contrast the findings among the four participating hospitals. Anonymity of persons and hospitals was maintained in all reports emanating from this research.

The researcher distributed the questionnaires to the respondents in the different hospitals and explained the reason for the study, and to get a high return rate of completed questionnaires. In order to assist respondents to be as honest and objective as possible in their responses, the completed sealed questionnaires were deposited in sealed boxes to which only the researcher had access. There was no threat to the respondents' anonymity at any stage of the research process.

\section{Reliability}

Polit and Hungler (1993:411) agree that the reliability of an instrument is its ability to create reproducible results: thereby being equated with the dependability, consistency or stability of a measuring instrument. Reliability is the extent to which the respondents consistently provide the same results, regardless of who does the measurement and when or where it occurs. In this study an attempt was made to ensure that the measuring instrument was reliable by adopting the following strategies:

- In the pretesting phase, the respondents were asked to identify typing errors, ambiguity of questions, problems of comprehension which could occur.

- The researcher distributed the questionnaires to the respondents in the different hospitals, specifically to explain the reason for the study. The respondents were also requested to be as objective as possible. They were assured of their anonymity so that they could make contributions by clearly identifying problems regarding cost containment.

- In order to assist the respondents to be as honest and objective as possible in their answers to the questionnaire items, it was arranged that completed questionnaires, sealed in envelopes supplied with the questionnaires, would be deposited in sealed boxes to which no person other than the researcher had access.

- A number of open-ended questions were included in the questionnaire in which respondents could freely add whatever they deemed necessary. This was done to further enhance respondents' free/open expression of their perceptions. (The respondents made good use of these open-ended items and provided a number of new ideas. The responses to the open-ended questions were analysed by categorising similar open-ended responses into groups.

These responses are portrayed in relevant sections under the discussion of the research results.)

- As explained under "ethical considerations", there was no threat to the respondents' anonymity at any stage of the data-collection process and the research process in general.

\section{Validity}

Validity refers to the degree to which an instrument measures what it is intended to measure (Dempsey \& Dempsey 1992:73; Polit \& Hungler 1993:448). Three main approaches for estimating the validity of a measuring instrument designed to collect quantitative data, are construct validity, criterion-related validity and content validity (Dempsey \& Dempsey 1992:73).

\section{Construct validity}

Construct validity is the degree to which a measuring instrument measures a specific hypothetical construct, for example, intelligence (Dempsey \& Dempsey 1992:73). The items included in the questionnaire were based on information obtained during the literature review. This implies that most items had been tested and accepted to be valid by other researchers, and the eleven participants in the pretest provided further support to the validity of the constructs addressed in this research project.

\section{- Criterion-related validity}

Criterion-related validity refers to the relationship between the measuring instrument and some already known external criterion (Dempsey \& Dempsey 1992:73). The external criterion in this research was hospital cost containment. Independent evaluators from Unisa, the University of Port Elizabeth and Vista University agreed that the questionnaire items were relevant to nurse managers' perceptions of hospital cost containment issues.

\section{- Content validity}

Content validity of a measuring instrument is the extent to which the instrument represents those factors under study. In this study content validity was assessed to establish whether the items on the instrument were representative of questions that should be asked about cost containment (Dempsey \& Dempsey 1992:73). In the construction of the questionnaire the following aspects were considered:

- Questions were formulated in simple language for clarity and ease of understanding.

- Clear instructions were given to respondents.

- Respondents were given sufficient time to complete the questionnaires.

For validation, the instrument was submitted to two researchers and one statistician at Unisa. A copy of the in- 
strument was given to a senior lecturer at the University of Port Elizabeth's Department of Nursing Science. Another copy of the instrument was given to a senior lecturer at the Department of Economics at Vista University, Port Elizabeth. Copies were also given to three nurse managers of hospital $\mathrm{D}$ for their evaluations concerning the validity of the questionnaires.

As a result some items of the instrument were eliminated as being irrelevant to the study. Rephrasing of some items was done in order to clarify the questions. Some of the items were restructured to reduce potential ambiguities.

\section{Ethical considerations}

Studies involving human respondents raises unique sets of ethical issues. According to Polit and Hungler (1993:435), the term "ethics" refers to the quality of research procedures with respect to their adherence to professional, legal and social obligations to the research subjects. Ethical standards and their acceptability were considered throughout the interaction of the researcher with participants involved in the research. The purpose of the study was explained to each group of respondents while they were being orientated to the study.

It was clearly stipulated to the respondents that participation in the study was important but voluntary. Nobody would be forced to answer any specific item. They were not subjected to any form of pressure to complete the questionnaire (Ntlabezo 2003:83-86). The researcher arranged discussions with groups of nurse managers in the different hospitals to give detailed descriptions of the nature of the study and to discuss the questionnaire, the aim of the study and the anticipated benefits the study would have for the nursing profession generally and for enhancing cost containment capabilities of nurse managers specifically. The respondents were assured that the responses would be treated confidentially and anonymously. The researcher could not identify the responses on any questionnaire as belonging to any specific person. The hospitals where the research was carried out would also not be named, and no information would be portrayed about separate hospitals but only about the four hospitals combined. The researcher kept all completed questionnaires locked up. The only persons who had access to these completed questionnaires were the researcher and the statistician who transferred the data to the SPSS (Statistical Package for Social Science) software computer program. All completed questionnaires were destroyed by the researcher after the research report had been accepted.

Permission to conduct the study was sought and obtained from the

$$
\begin{aligned}
& \text { - } \quad \text { regional director of region } \mathrm{A} \text { in the Eastern Cape } \\
& \text { medical superintendents of the different hospitals } \\
& \text { participating in the study }
\end{aligned}
$$

Individual letters were written to prospective respondents who were addressed as "colleagues" in the letters and no names were indicated as the letters were delivered by hand. This measure was carried out to ensure anonymity of respondents as well as confidentiality.

\section{Research results and discussion}

The analysis and discussion of the research results as such will be preceded by some biographic information about the respondents in order to contextualise the research results against the background of who the respondents were.

\section{Biographic information}

The results showed that $68,6 \%$ of the respondents had more than five years of experience, with an average of 17,5 years. It could thus be assumed that these respondents were knowledgeable about managing hospital wards and departments in the hospitals and that they should thus also be knowledgeable about cost containment issues.

\section{Preparation/Orientation towards cost containment}

Regarding the respondents' perceived orientation towards financial management training, it was found that the following aspects required further attention, as indicated by the percentages of respondents who claimed to be fully prepared (given in brackets):

- preparation of a hospital budget $(6,6 \%)$, and manpower budget $(6,2 \%)$

- $\quad$ general principles of cost containment in the hospi$\operatorname{tal}(10,7 \%)$

- $\quad$ ordering and purchasing of supplies and new equipment $(41,3 \%$ and $18,9 \%)$, and orientation of staff about the use thereof $(35,2 \%)$

- availability of prices for commonly used items (35 $\%)$, hospital's operational costs $(23,5 \%)$, and capital costs $(9,7 \%)$.

"Financial thinking skills are the cornerstone of cost conscious nursing practice..... and nurses must determine whether the services they render are of high quality, positively affect health outcomes and minimize costs"(Westmoreland 1995:270). The preparation of a hospital's budget, the nursing manpower budget per unit as well as general principles of cost containment are presently included in formal programmes for training nurse managers. As supplies are regarded as the second most significant budget factor, nursing expertise is needed to avoid over- or underspending. Reportedly more use should be made of the representatives from the sales companies to demonstrate a newly acquired piece of equipment to as many staff members as possible. If nurse managers are not aware of the hospital's operational costs to some extent, they would find it virtually impossible to motivate nurses to keep costs down. At the very least monthly variance reports should be distributed to each unit in order to compare expenditures with monthly and annual allocations (as 
specified in the monthly and annual budgets). If managers are sufficiently informed about the hospital's strategic plans, including projected capital expenditure, they would be in a position to guide unit staff, where capital expenditure requests originate. In this way requests for capital items which could not be considered by the budgeting committee could be limited. A recommendation would thus be that at least the manager at top level management should have adequate knowledge about different budgets, including the daily expenditure, capital, nurse manpower, as well as the supplies and equipment budget in order to be able to give significant inputs in committees where costs are discussed. Regarding the availability and visibility of prices for commonly used items, it is recommended that prices should be indicated on ordering lists, on stock cupboards, and on monthly balance sheets issued to each hospital department. The reasons why the nurse managers were not knowledgeable about these aspects could not be ascertained, especially since $68,6 \%$ of the 156 respondents had more than five years' experience, and the average number of years of experience was calculated to be 17.5 years (Ntlabezo 2003:91).

\section{Nurse managers' perceptions about their cost containment functions}

The respondents $(69,9 \%)$ indicated that the nurse manager should be involved in the planning of a hospital budget; that information about increases in consumable costs in units and departments should be supplied to top management $(94,7 \%)$; that in-service education sessions on cost containment should be held on a three-monthly basis for all categories of nurses $(96,2 \%)$; that non nursing departments should be included in meetings regarding cost containment $(76,9)$. However, the respondents did not know what actions should be taken in the case of an unplanned, non-budgeted or unexplained escalation of consumable costs in a unit as $54,3 \%$ indicated that the medical superintendent would be called upon to investigate the probable cause(s).

\section{Nurse managers' perceptions of costs versus productivity in health services}

Most of the respondents, namely $84,7 \%$, were aware of the interrelatedness of costs and productivity in general. Regarding the motivation of staff, $62,7 \%$ of the respondents agreed that during times of staff shortages, the motivation level of nurses was the decisive factor determining whether or not quality care continued to be rendered. This was the case because motivated staff members would strive to continue rendering the best possible quality of patient care in spite of staff and/or equipment shortages, whereas unmotivated staff members would be unlikely to do so. Of the nurse managers $71,3 \%$ supported the use of incentives to reward nurses who rendered outstanding work. Although such rewards might imply additional costs, the long term motivation factor attached to such rewards might indeed offset these costs. The performance of non-nursing tasks by nursing personnel was not favoured by $97,6 \%$ of the respondents, as this could contribute to the escalation of costs. Non-nursing tasks could be performed more costeffectively by non-nurses. Most respondents $(92,3 \%)$ recognised the need for maintaining continuous education of nurses, even during times of staff shortages. Failure to maintain continuous education could be more costly in the long term than the short term expenses involved in offering such education opportunities to nurses.

\section{Personnel issues influencing hospital cost containment efforts}

Three personnel problems, causing escalations in health care costs, were identified, namely staff leaving their points of duty during duty hours, absenteeism and resignations.

\section{Nurses leaving their points of duty during duty hours}

Surprisingly $75,0 \%$ of the respondents stated that they believed that nurses should be allowed to leave their points of duty during duty hours to some extent. Many respondents $(85,6 \%)$ indicated that nurses' leaving their points of duty because family members had taken ill, were justified actions. In a similar trend as many as $69,7 \%$ respondents believed that nurses' leaving their points of duty to attend to personal problems was acceptable. Although no reasons could be ascertained for this perception, it is possible that nurse managers who accept nurses' absence from their points of duty to attend to their personal problems, could contribute to the escalation of hospital costs as additional staff members would be required to fulfil the duties of these absent nurses. Such additional staff members could require the payment of "overtime" or could be obtained from nursing agencies at increased costs.

\section{Absenteeism}

Approximately half $(50,3 \%)$ of the nurse managers indicated that regular surveys about staff absenteeism were not done. The respondents regarded reasons like personal illness $(95,8 \%)$; death of a family member $(90,1 \%)$; a sick family member $(79,7 \%)$; looking after children $(40,7 \%)$ and family violence $(39,1 \%)$ as acceptable reasons for being absent from work. Being absent from work because of frustrations and stresses at work, was considered to be unacceptable by $88,1 \%$ of the respondents.

Most respondents $(92.8 \%)$ would implement proposals received from management and personnel to reduce staff absenteeism, and would provide feedback to the nursing personnel about the implementation of such proposals. Only $46.6 \%$ of the nurse managers would write notices to the effect that all nurses absent from duty would not be paid for the period of absence. The respondents indicated that the following arrangements were made to ensure coverage of patient care when there was a high rate of absenteeism between shifts:

\footnotetext{
- Rearrange staff off-duties.

- Counsel staff on incidences of late arrivals and early departures.
} 
Make staff work back the time (number of hours) during which they were absent.

- Make use of volunteer workers.

- $\quad$ Motivate for more staff to be employed.

Maintaining accurate records of absence data would serve to monitor the problem and to detect patterns of absenteeism in each organisation and in each unit. Such records might also help to identify unknown reasons for absences.

\section{Resignations by nurses}

As nurses constitute the largest professional group of health care workers in hospitals, the resignations by nurses requiring recruitment and selection costs, could contribute towards hospitals'costs. Should the resignation of nurses necessitate the use of agency, contract or overtime payments, hospitals' cost containment efforts could be seriously jeopardised. Nurse managers ranked the following reasons for nurses' resignations according to their perceived order of importance:

- family matters, such as transfer of spouse (99\%)

- $\quad$ ill-health $(98,1 \%)$

- $\quad$ insufficient salary $(97,1 \%)$

- domestic demands $(93,3 \%)$

- $\quad$ intentions to change careers $(90,4)$

- dissatisfaction with working conditions $(86,5 \%)$

If the categories "dissatisfaction with working hours" $(77,4 \%)$ and "inconvenient working hours" $(78,8 \%)$ were to be considered jointly, this would be the most important reason for nurses' resignations. It is recommended that crèches should be made available for nurses in order to curb resignations, as well as absence from duty, due to childcare responsibilities.

\section{Control of supplies, equipment and stock losses}

The majority of the respondents $(94,8 \%)$ knew about the importance of standardised procedures to keep costs down. Periodic inspections of stock cupboards $(93,4 \%)$ and inspecting the ordering records $(91,4 \%)$ in order to pick up any errors of recording and storage were also considered important in managing the equipment and supplies effectively. A high level of importance $(88,6 \%)$ was also attached to keeping keys of supply cupboards on the person while on duty, in order to prevent stock losses.

Additional suggestions for controlling supplies and thereby enhancing hospitals' cost containment efforts, as listed by respondents, included:

- Order sufficient supplies each time.

- Identify supplies by marking each item with the name of the specific hospital unit.

- Keep supplies under lock and key.

- Use appropriate procedures for effective treatment.

- Prevent unnecessary cancellation of operations

All these suggestions would help to curtail hospital ex- penses and enhance hospitals' cost containment efforts.

\section{Equipment}

Respondents perceived cost containment efforts to involve at least the following:

- $\quad$ Providing a sound motivation for the purchase of a piece of equipment

- Careful analysis of what is offered on the market, ensuring good prices but also effective after-sales service

- Taking into account the item's projected life span

- $\quad$ Placing the piece of equipment on trial to identify faults while the equipment is still under gaurantee from the supplier

- Submission of new equipment to be rechecked for faults by personnel who have specific skills, if it is still under guarantee.

- $\quad$ Recheck the piece of equipment for faults by personnel who know how it functions

- Marking all new equipment with the unit's name before use.

All these measures could help to contain hospitals' costs by buying the required equipment at the best prices possible and by ensuring the best possible after-sales service and by counteracting the possible losses of equipment.

Additional methods suggested by respondents were:

- Keep a record of equipment borrowed from each ward/unit in order to check that such items are indeed returned.

- Invite discussions and suggestions concerning the control of general equipment.

- Make sufficient equipment available.

\section{Control of stock losses}

Respondents perceived the following methods to be important:

Maintain stock books up to date and conduct monthly inventories $(97,3 \%)$, institute disciplinary actions against those who remove items without due authorisation $(95,3 \%)$, apply security measures at hospital entrances $(89,1 \%)$ and put up notices about the unauthorised removal of items $(88,6 \%)$. Additional methods suggested in response to an open-ended question included the use of record books when lending items to another unit and stock items for identification purposes. It was also recommended that people entering and leaving the hospitals should be screened by security officers. Effective security checks at hospital entrances and exits could significantly reduce stock losses.

\section{Control of wheelchairs}

The availability of wheelchairs in hospitals is of the utmost importance, as wheelchairs are considered a means of easy transport for patients from one unit to another in a hospital. They are also expensive items to purchase and to maintain. The majority $(97,1 \%)$ of the respondents considered the maintenance of wheelchairs to be the most important as- 
pect for containing costs in this category of equipment. The second most important aspect was reportedly keeping a monthly inventory of all wheelchairs and reporting any losses $(92,7 \%)$. Keeping a centralised storage space for wheelchairs $(80,1 \%)$, and signing a register whenever using a wheelchair $(84,5 \%)$ could help to combat the loss of wheelchairs. Respondents suggested other methods of control of wheelchairs, in response to an open-ended question, including:

- having security personnel available to control wheelchairs

- involving community members in the control of wheelchairs

- $\quad$ identifying each wheelchair by marking it with the name of the department/unit

- taking stock of wheelchairs daily

\section{Control of telephone use}

The telephone can be misused by staff members making unauthorised calls, resulting in the hospital's incurring huge telephone bills. The majority of the respondents $(91,9 \%)$ favoured monthly printouts of the frequency and duration of each unit's use as well as inservice training $(90,5 \%)$ to make staff aware of the importance of controlling telephone costs. The installation of more public telephones in the hospital grounds was suggested by a number of respondents. This seemed to be the logical solution, as staff members could then use these telephones for their private calls.

\section{Nurse managers' possible contributions towards cost containment efforts in public hospitals}

Additional suggestions provided in response to openended questions, about ways in which nurse managers could contribute to hospitals' cost containment efforts, included:

- $\quad$ providing a safe physical environment in the hospital to prevent patient injuries and subsequent costly litigations

- $\quad$ reducing the number of available hospital beds in accordance with the number of available nurses

- $\quad$ presenting regular courses on financial management to all nurse managers

- allocating nurses to appropriate units for optimum productivity

- applying good management techniques

- $\quad$ giving incentives to good performers

- rationalising staff and services among the four hospitals so that specific specialist services are rendered only at one of these hospitals, in stead of being duplicated in all four hospitals

- $\quad$ using pieces of equipment solely for the intended purposes

- $\quad$ purchasing items on tender bases only

- decreasing patients' hospital periods.

\section{Limitations of the study}

This study was confined to four provincial (state) hospi- tals in the Port Elizabeth Metropole of the Eastern Cape. Limiting the number of hospitals does, however, limit the generalisability of the findings. Questions formulated for the questionnaire were based only on those aspects which were considered to be the most common causes of escalating costs in provincial hospitals, based on the literature reviewed and on discussions with a number of nurse managers. Many other issues, including the use/misuse of transport services, and the efficiency of various other services in a hospital - such as the pharmacy, radiography, and physiotherapy departments - could affect the success or failure of a hospital's cost containment efforts. These issues were not addressed in this study because nurse managers performed no specific cost containment roles within these specialised departments.

\section{Conclusions}

The conclusions presented according to the research questions formulated for this study, are:

- The nurse managers perceived their preparation/ orientation to cost containment in provincial hospitals to be inadequate.

- The nurse managers' perceptions about the importance of motivation and productivity of staff were positive, being aware of their effects on containing costs in public hospitals.

- $\quad$ Nurse managers encountered serious problems with nurses' "temporary" absences from points of duty, as well as with absenteeism among staff members, and the costs and inconvenience incurred, but were apparently unable to address these issues successfully.

- Nurse managers indicated positive perceptions regarding the acquisition and control of supplies and equipment, but whether they would be able to implement these suggestions in practice could not be judged from their responses to the questionnaires.

- The nurse managers viewed the misuse of telephones and wheelchairs in a serious light.

- Additional general cost containment measures suggested by nurse managers were realistic and included various ways for containing costs.

\section{RECOMMENDATIONS}

Cost containment in public hospitals could benefit if the

- the training and orientation of nurse managers about cost containment issues could be improved

- motivation of nurses could be maintained, even during difficult times

- $\quad$ temporary absences of nurses from their points of duty as well as absenteeism among nurses should be addressed as a matter of urgency; nurse managers need to be empowered to deal more effectively with these issues

- hospitals should provide childminding facilities for their staff members

- acquisition and control of supplies were managed 
effectively on a continued basis

- $\quad$ use of telephones and wheelchairs would be managed more effectively

- rationalisation of specialised services among the four hospitals could be implemented.

The major contribution which nurse managers could make towards containing costs in public hospitals would be to manage absenteeism among nurses more effectively as well as combating nurses' reported absences from their points of duty. Factors contributing to resignations among nurses should be identified and addressed in an effort to reduce the staff turnover rates among nurses.

"Nurse managers are the key to the success of hospital organization. It is critical that individuals in this role have the behavior skills needed to carry it out effectively" (Chase 1994:64). Finally and fundamentally, it can be stated that "nurse administrators and educators have formidable challenges ahead. Monitoring and evaluating role changes while maintaining a healthcare system that is caring, ethical, health-promoting, and cost-effective is the future task" (Krejci 1999:29).

\section{References}

BULTEMA, JK 1995: Theory, quality and economy: a winning combination. Journal of Nursing Administration. 25(7):38-45.

CAROSELLI, C 1996: Economic awareness of nurses: relationship to budgetary control. Nursing Economics. 14(5):292-298.

CHASE, L 1994: Nurse manager competencies. Journal of Nursing Administration. 24(48):56-64.

COILINS THESAURUS, 1993: Glasgow: Harper Collins.

DEMPSEY, PA \& DEMPSEY, AD 1992: Nursing research with basic statistical applications. $3^{\text {rd }}$ edition. Boston: Jones \& Bartlett

HORVATH, KJ; SECATORE,JA; AI PERT, HB; COSTA, MJ; POWERS, EM; STENGREVICS,SS \& AROIAN, J 1994: Uncovering the knowledge imbedded in clinical nurse manager practice. Journal of Nursing Administration. 24(7/8):39.44.

KREJCI, JW 1999: Changing roles in nursing. Journal of Nursing Administration. 29(3):21-29.

NTL_ABEZO, ET 2003: Nurse managers' attitudes and perceptions regarding cost containment in public hospitals in the Port Elizebeth Metropole. Pretoria: University of South Africa. (D Litt et Phil thesis).

POIIT, F \& HUNGLER, BP 1993: Essentials of nursing research: appraisal and utilization. $3^{\text {rd }}$ edition. Pennsylvania: JB Lippincott.
SENGIN, KK \& DREISBACH, AM. 1995: Managing with precision: a budgetary decision support model. Journal of Nursing Administration. 25(2):33-44.

THE OXFORD HANDY DICTIONARY, 1991. London: Chancellor Press.

WARREN, IB \& ROZELLE, BR 1995: Supplemental staffing: nurse manager views of costs, benefits and quality of care. Journal of Nursing Administration. 25(6)5 I-57.

WESTMORELAND, D 1995: Managing costs and budgets. (In Yoder-Wise, PS Ed. 1995: Leading and managing in nursing. St Louis: CV Mosby).

YONDER-WISE, PS (ed) 1995: Learning and managing in nursing. St Louis: CV Mosby.

ZACHRY, BR, GII BERT, RI \& GRAGG, M 1995: Director of nursing finance: controlling health care costs. Nursing Management. 26(11):49-54. 